\title{
Advances and trends in two-zone fluidized-bed reactors
}

\author{
J. Herguido, M. Menéndez
}

Catalysis, Molecular Separations and Reactor Engineering Group (CREG) Aragón Institute of Engineering Research (I3A) - Universidad Zaragoza

C/ Mariano Esquillor s/n, Zaragoza (Spain)

$\left({ }^{*}\right)$ miguel.menendez@unizar.es

\begin{abstract}
Two-zone fluidized bed reactors, devices to carry on two reactions in a single reactor, have been widely studied in our group. This work summarizes the developments achieved after a previous review published in 2005 and shows how this technology can be applied in a wide variety of reactions. The advantages for each kind of process are discussed, as well as several proposals for improvement of the reactor aimed to achieve new functions or to improve the process performance. Finally, the possibilities of this kind of reactors at industrial scale are discussed.
\end{abstract}

\section{Introduction}

A two-zone fluidized bed reactor (TZFBR) is a device in which two chemical reactions are made simultaneously: one of the reactions is carried in the upper zone and other reaction in the lower zone. The formation of two zones with different reaction environment is achieved by feeding two streams with different composition, one of them to the bottom of the fluidized bed and the other to an intermediate point of the fluidized bed. The difference with the conventional fluidized bed reactor is shown as the comparison of Figure $1 \mathrm{a}$ and Figure $1 \mathrm{~b}$. The gas bubbles, as is usual in fluidized beds, transport solid between the two zones, in such a way that each particle alternatively remains some time in each zone. Although other systems have been described in literature where there is a transport of solid between fluidized beds, as reviewed in [1], the TZFBR is different because it creates two zones, making a different reaction in each zone, in a single vessel.

In a previous review [2] we presented the developments made in our group in the field of TZFBRs. The different kinds of reactions to which the TZFBR was applied, as was described in that review, are shown in Table 1. These reactions can be divided in two groups: a) Reactions in which the catalyst acts as oxygen carrier, e.g. oxidative coupling of methane. In that case the catalyst is oxidized with oxygen in the lower part of the reactor and the catalyst transports oxygen in the crystalline lattice to the upper part of the reactor, where a desired catalytic oxidation is carried out using the oxygen from the solid structure (thus reducing the solid); b) Reactions in which the catalyst is deactivated by coke during the desired reaction, e.g. alkane dehydrogenation. In that case the catalyst is regenerated by an oxidizing gas in the lower zone of the reactor. The catalyst transports coke from the reaction zone to the regeneration zone. 
The articles included in that revision showed how the use of a TZFBR can provide significant advantages over conventional reactors. In some cases it was possible to counteract the catalyst deactivation and achieve steady state operation in the TZFBR, while conversion continuously decreased in a conventional reactor. In other cases the TZFBR allowed the operation with higher oxygen/hydrocarbon ratio than a conventional reactor with cofeeding of reactants, because it avoided the premixing of reactants that could generate explosive mixtures. In some cases the TZFBR provided higher selectivity to the desired product for a given degree of conversion than the conventional reactor.

The modeling of this type of reactors was started using a simple mathematical model [3] based on the Kunii-Levenspiel model [4] for fluid dynamics of fluidized beds, but accounting for the reaction kinetics for the main reaction, the catalyst deactivation, the kinetics for the coke removal and the solid transport between the reaction and the regeneration zones.

Although most of the work in TZFBR has been developed at the University of Zaragoza, several groups have started to test this kind of reactor and have confirmed that the TZFBR can sometimes provide advantages over conventional reactors. Talebizadeh et al [5] have shown the use of this reactor for oxidative coupling of methane. These authors found improved selectivity to the desired products in the TZFBR over the conventional reactor. This is interesting because in our previous work [6] such improved selectivity was not achieved with another catalyst, although it was possible to have separate zones for the catalyst oxidation and the oxidative coupling reaction. Also Rischard et al [7][8] have found that with one of the tested catalysts the TZFBR provides improved selectivity in oxidative dehydrogenation of butane to butadiene. It is remarkable that the improved selectivity was not obtained with all the tested catalysts, which shows the need to test for each specific application and catalyst if the TZFBR improves the yield to the desired product. Finally, the use of TZFBR has also been proposed [9] for the decomposition of maleic anhydride.

The next section will show the developments made by our group in the field of TZFBR, both checking the feasibility of its use in new reactions and reactor configurations, and in new contributions to the modeling of this kind of reactors.

\section{Recent developments}

\subsection{New reactions}

\section{Methane Steam Reforming}

Methane steam reforming (MSR) is currently the main industrial process for hydrogen production. Coke formation may be a problem in this process if it operated with low steam/carbon ratio. Although some procedures have been proposed to reduce carbon formation [10][11], the risk of carbon formation is still a major issue in industrial reactor operation. The usual way to avoid this risk is to operate with high steam/carbon ratio, but this procedure implies high energy consumption. We have found [12] that steady state operation in a TZFBR is possible, carrying out the desired reaction (i.e. steam reforming) in the upper zone and using steam to fluidize the lower zone and also as regenerating agent. In that case, 
the removal of coke is made by steam instead of oxygen. In that way, it is possible to operate in steady state with a feed (considering the sum of the two feeds in the TZFBR) that would cause catalyst deactivation in a conventional reactor. A wide study of the operating conditions, showed they effect on hydrogen yield, as well as the operation limits to obtain steady state operation [13]. The use of water as regenerating agent was a main novelty of this work, since in previous works we always used oxygen as the reactant for coke removal. Figure 2 shows the stability achieved in MSR, as well as in other processes that will be mentioned below.

\section{Ethanol steam reforming}

Steam reforming of ethanol has been proposed [14-17] as a suitable procedure to produce hydrogen from a high density fuel, which in addition can be obtained from renewable sources. This could be applied in mobile applications, e.g. as the source of hydrogen to be employed in fuel cells for cars, or other applications where the amount of hydrogen needed is not too high, but there is not natural gas available (e.g. remote locations). A problem of this reaction is the high tendency towards coke formation if the steam/ethanol ratio is not high enough. It is obvious that the operation with high steam/ethanol ratios implies a high energy consumption to produce steam, and if water should be transported that would mean an additional expense. We have shown [18] that steam reforming of ethanol can be performed under operating conditions that would cause coke formation in a conventional reactor, by using a TZFBR. This application is quite similar to the methane steam reforming previously shown.

\section{Hydrogen purification by PROX}

Hydrogen produced industrially by steam reforming, even after a stage of water gas shift to decrease the $\mathrm{CO}$ concentration, contains small amounts of $\mathrm{CO}$ that must be removed to achieve the quality required in a PEM fuel cell. One of the existing procedures to remove these traces of $\mathrm{CO}$ is the PReferential OXidation (PROX) reaction, in which CO is oxidized with oxygen in the presence of a selective catalyst [19-21]. Obviously, oxygen can also react with hydrogen, which is present in much higher concentration than $\mathrm{CO}$, which implies an undesirable consumption of hydrogen. Usually an amount of oxygen larger than the stoichiometric one required for the removal of $\mathrm{CO}$ is feed, in order to compensate the oxygen lost in hydrogen combustion. The closer the amount of oxygen to the stoichiometric amount required for $\mathrm{CO}$ combustion, the higher the catalyst selectivity. We have shown [22] that a selective oxidation of $\mathrm{CO}$ can be obtained by using a TZFBR. Probably this improved selectivity is achieved because the reaction is carried by using, at least in part, oxygen from the catalyst structure instead of oxygen from gas phase. This would be an application in which the catalyst acts as oxygen carrier between the lower zone of the reactor, where the catalyst oxidation is produced and the upper zone, where the desired reaction is carried out.

\section{Benzene oxidation to phenol}

The direct oxidation of benzene to phenol has been the target of many researchers [23-25]. A catalyst able to achieve this reaction in a single step would be very useful, because it would avoid the cumbersome process currently employed. We have found that the TZFBR can be employed for this reaction, and that the product distribution drastically changes depending on the operation conditions [26]. However, the achieved conversions were too low, and an 
industrial process does not seem to be feasible, at least with the catalyst employed in that work.

\section{Methane aromatization}

The production of liquid fuels from natural gas has a strong economic potential. Some industrial processes that are already being employed are the production of diesel fuel by Fischer-Tropsch process and methanol production. Transformation of methanol to olefins is employed in several industrial plants in China. Another process with great potential is the direct transformation of methane to benzene. Although numerous attempts to achieve a catalyst that does not suffer deactivation by coke have been published [27] since the original work of Wang et al. [28], this problem has not been solved. We have found [29,30] that a TZFBR can be employed for methane aromatization, by feeding a small amount of oxygen to the bottom of the reactor. In this way, steady state operation was achieved, compensating the catalyst deactivation, which is one of the main hindrances that avoid the industrial deployment of this process.

\section{Cleaning of biomass gasification product}

The gas obtained by biomass gasification contains hydrogen and carbon monoxide, making it suitable for liquid fuels production, but contains a too large amount of tar. The use of a TZFBR as a way to clean this stream has been tested experimentally [31]. The gas from the gasification reactor was depleted from tar, which was deposited on the surface of the catalyst in the upper zone of the TZFBR. Simultaneously, tar was removed in the lower zone of the TZFBR.

\subsection{New reactor configurations}

\section{Two-sections TZFBR}

The bed diameter was the same in the lower and in the upper zone in the first designs of TZFBR. This fact implied the need for a large gas flow in the lower zone to keep it fluidized, and a much larger flow in the upper zone, since the reactant feed introduced at a central point of the reactor was added to the flow coming from the bottom zone. The flow of gas needed to keep the bottom zone fluidized was larger than the one needed to regenerate or oxidize the catalyst. We have proposed $[28,29]$ a change in the design of the reactor based on the use of two sections with different diameter. This configuration is represented in Figure $1 \mathrm{~b}$. The advantage of this design is that it allows operating with a lower flow in the lower zone, which can be adapted to that need for regeneration or catalyst reoxidation, usually much lower than the flow of the main reactant.

\section{TZFBR with membranes}

Membrane reactors are a well-known case of process intensification, since they combine in one single equipment a chemical reaction and the separation achieved with the membrane $[32,33]$. In one of the most studied types of membrane reactor the membrane removes one of the reaction products from the catalyst bed, helping to achieve higher conversion, often higher than that corresponding to the thermodynamic equilibrium in a conventional reactor. A well- 
known example is the use of palladium membrane reactors to remove hydrogen in reactions where it is one of the products. A problem that is often found in this type of reactors is that the removal of hydrogen increases the catalyst deactivation by coke [34]. We have proposed to combine a TZFBR with a palladium membrane. This configuration is represented in Figure 1c. Although fluidized bed reactors with palladium membranes had been described [35], the advantage of the combination with TZFBR consists in the simultaneous regeneration, which makes possible the steady state operation in conditions where a conventional membrane reactor would suffer deactivation by coke. The combination of TZFBR with membranes (TZFBR+MB) is an outstanding case of process intensification, since it allows making three simultaneous operations in one single device: a) the catalytic reaction to obtain the desired product, b) the catalyst regeneration, and c) the separation of one of the reaction products. This has been achieved with several types of membrane, such as palladium membranes over ceramic hollow fibre [36][37] or commercial palladium membranes over a porous metallic support [38]. Recent results for dry reforming of methane [39] show a two fold increase in hydrogen yield using TZFBR+MB, compared with a TZFBR, and also the capacity to achieve steady state operation under conditions where a conventional fluidized bed reactor was deactivated by coke. An additional advantage of TZFBR+MB is that the hydrogen that permeates through the membrane has a high purity.

\subsection{New contributions to modelling of TZFBR}

We used a mathematical model with constant bubble size in our first work on the modelling of TZFBR [2]. This is a clear simplification over the real situation in a fluidized bed, since the bubble size increase along the fluidized bed. This simplification was removed later [40], thus providing a more realistic model .

Otherwise the use of a TZFBR or a two sections-TZFBR implies a significant change in the gas and solid flow, compared with a conventional reactor. Therefore, additional studies have been carried out to achieve a better knowledge of the fluid-dynamic parameters. We found that it was possible to modify the classical models, describing the bubble size variation with height in a conventional fluidized bed, to predict these properties along a TS-TZFBR [41]. Another fundamental point for the modeling of the reactor is the transport of solid between zones. Solid mixing has been studied with phosphor particles [42] and using Particle Image Velocity (PIV) $[43,44]$. These contributions to the knowledge of their fluid-dynamics provide a suitable basis for improved mathematical models of TZFBR.

\subsection{Overall comparison of performance}

Figure 3 gives an overview of the performance (yield to the desired product) achieved in TZFBR compared with the conventional Fluidized Bed Reactor (FBR). The time-on-stream selected for plotting FBR performances is $t_{f}$ (see fig. 2). This time corresponds to around 3 hours for most of the processes. Evidently, with regard to the most unstable processes (such as BDH, PDH or $M A)$, the higher the time-on-stream the lower would be the obtained $Y_{i}$ value, and consequently a progressive displacement over time of related symbols in Fig. 3 to the left side of the graph could be expected.

Regarding the Dry Reforming of Methane, there is not an increase in the hydrogen yield when TZFBR was used with respect to the FBR case. The reason was the stability found in the FBR at the selected experimental conditions, i.e., even though a net formation of coke is taking place 
in the bed, no clear decrease in activity is appreciated during the runs $\left(t_{f} \approx 3 h\right)$, as it can be seen in Figure 2, because the high spatial time. For this process, when hydrogen is removed by means of permselective membranes (TZFBR+MB) this stability can only be maintained thanks to the regenerating effect provided in the TZFBR. Otherwise, increased coke production due to the removal of hydrogen from the reacting atmosphere, would lead to a drastic drop in activity regardless the high spatial time. The huge effect of membranes on the yield to hydrogen can be clearly seen in Figure 3 . The higher the surface of membranes, and consequently the flow of hydrogen removed from the bed, the higher is the yield to hydrogen. So, in addition to providing a stable operation over time-on-stream, much higher hydrogen yields have been attained over the entire range of temperatures. Moreover, most of the hydrogen produced (around $70 \%$ for TZFBR+MB and around $85 \%$ for TZFBR $+\mathrm{nMB}$ configurations) is a permeate stream pure enough (negligible contents of $\mathrm{CO}$ ) to be used in low temperature fuel cells for automotive applications.

\section{Future prospects}

Although the first description of a TZFBR can be traced back to a patent from 1976 [45], no one is still employed industrially, at least with a clear purpose of creating two zones with different atmosphere with a different reaction in each zone. In some catalytic fluidized bed reactors, employed for selective oxidations, the oxygen is fed at the bottom and the hydrocarbon in an intermediate point; however, the aim seems to be only to avoid the premixing of reactants, for a safer operation.

Factors that have hindered the industrial use of TZFBR could include: a) The perception of risk associated to feeding an oxygen containing gas to a vessel where hydrocarbons are also fed, b) The consideration of fluidized bed reactors as difficult to design in general, and even more for a new reactor where the gas and solid flow were unknown, c) The lack of expertise in this kind of reactors.

Several factors can make easier the implementation of TZFBR in the industry in the future: a) The large number of reaction systems where TZFBRs have been tested in the last two decades, b) The improved knowledge of the gas and solid flow, which provides a tool for reactor upscaling. As explained in section 2.3, it has been shown that CFD models can predict the gas and solid flow. In addition, new correlations for gas and solid flow are available. c) The feasibility of using other gases different from oxygen in the lower zone of the reactor (e.g. water or $\mathrm{CO}_{2}$ ), which avoids the concerns about the risks associated with feeding to a device a fuel and a gas containing oxygen, and d) the advantages that it could provide when combined with selective membranes, allowing a higher level in process intensification (reaction, catalyst regeneration, and products separation in the same vessel). As described in the introduction, some other groups have started to test the TZFBR as a suitable system for several reactions. All these factors pave the way for a first industrial application that could be the detonator for the implementation of TZFBR in a variety of processes.

\section{Acknowledgements}

Financial support from the Spanish Ministerio de Economía e Innovación (MINECO) through the project ENE2013-44350R is gratefully acknowledged. 


\section{REFERENCES}

[1] Rubio O, Herguido J, Menéndez M, Grasa G, Abanades JC. Oxidative dehydrogenation of butane in an interconnected fluidized-bed reactor. AIChE J 2004;50:1510-22. doi:10.1002/aic.10134.

[2] Herguido J, Menéndez M, Santamaría J. On the use of fluidized bed catalytic reactors where reduction and oxidation zones are present simultaneously. Catal Today 2005;100:181-9. doi:10.1016/j.cattod.2004.11.004.

${ }^{* *}$ Is the key to show the first developments in TZFBR

[3] Soler J, Tellez C, Herguido J, Menendez M, Santamarı J. Modelling of a two-zone fluidised bed reactor for the oxidative dehydrogenation of $\mathrm{n}$-butane. Powder Technol 2001;120:88-96.

[4] Kunii D, Levenspiel O. Bubbling bed model. Ind Eng Chem Fund 1968;7:446-52. doi:10.1021/i160027a016.

[5] Talebizadeh A, Mortazavi Y, Khodadadi AA. Comparative study of the two-zone fluidized-bed reactor and the fluidized-bed reactor for oxidative coupling of methane over Mn/Na2WO4/SiO2 catalyst. Fuel Process Technol 2009;90:1319-25. doi:10.1016/j.fuproc.2009.06.021.

[6] Ramos R, Herguido J, Menéndez M, Santamaría J. Oxidation of Hydrocarbons in an in Situ Redox Fluidized Bed Reactor. J Catal 1996;163:218-21.

[7] Rischard J, Antinori C, Maier L, Deutschmann O. Oxidative dehydrogenation of n-butane to butadiene with Mo-V-MgO catalysts in a two-zone fluidized bed reactor. Appl Catal A Gen 2016;511:23-30. doi:10.1016/j.apcata.2015.11.026.

[8] Rischard J, Franz R, Antinori C, Deutschmann O. Oxidative Dehydrogenation of Butenes over Bi-Mo and Mo-V Based Catalysts in a Two-Zone Fluidized Bed Reactor. AIChE J 2017;63:43-50. doi:DOI 10.1002/aic.

[9] Pariente S, Belliere-Baca SP, Paul S, Fatah N. Process for obtaining acrolein by catalytic dehydration of glycerol or glycerin. PCT/FR2011/052492, 2016.

[10] Rostrup-Nielsen T. Manufacture of hydrogen. Catal Today 2005;106:293-6. doi:10.1016/j.cattod.2005.07.149.

[11] Rostrup-Nielsen JR. Sulfur-passivated nickel catalysts for carbon-free steam reforming of methane. J Catal 1984;85:31-43. doi:10.1016/0021-9517(84)90107-6.

[12] Pérez-Moreno L, Soler J, Herguido J, Menéndez M. Stable hydrogen production by methane steam reforming in a two zone fluidized bed reactor: Experimental assessment. J Power Sources 2013;243:233-41. doi:10.1016/j.jpowsour.2013.05.197.

[13] Pérez-Moreno L, Soler J, Herguido J, Menéndez M. Stable hydrogen production by methane steam reforming in a two-zone fluidized-bed reactor: Effect of the operating variables. Int J Hydrogen Energy 2013;38:7830-8. doi:10.1016/j.ijhydene.2013.04.122.

[14] Ni M, Leung DYC, Leung MKH. A review on reforming bio-ethanol for hydrogen production. Int J Hydrogen Energy 2007;32:3238-47.

doi:10.1016/j.ijhydene.2007.04.038. 
[15] Verónica M, Graciela B, Norma A, Miguel L. Ethanol steam reforming using Ni(II)-Al(III) layered double hydroxide as catalyst precursor. Chem Eng J 2008;138:602-7. doi:10.1016/j.cej.2007.08.035.

[16] Vizcaino A, Arena P, Baronetti G, Carrero A, Calles J, Laborde M, et al. Ethanol steam reforming on Ni/Al2O3 catalysts: Effect of $\mathrm{Mg}$ addition. Int J Hydrogen Energy 2008;33:3489-92. doi:10.1016/j.ijhydene.2007.12.012.

[17] Romero A, Jobbágy M, Laborde M, Baronetti G, Amadeo N. Ni(II)-Mg(II)-Al(III) catalysts for hydrogen production from ethanol steam reforming: Influence of the activation treatments. Catal Today 2010;149:407-12. doi:10.1016/j.cattod.2009.05.026.

[18] Pérez-Moreno L, Soler J, Herguido J, Menéndez M. Stable steam reforming of ethanol in a two-zone fluidized-bed reactor. Ind Eng Chem Res 2012;51:8840-8. doi:10.1021/ie201968u.

[19] Gamarra D, Martínez-Arias A. Preferential oxidation of $\mathrm{CO}$ in rich $\mathrm{H} 2$ over $\mathrm{CuO} / \mathrm{CeO}$ : Operando-DRIFTS analysis of deactivating effect of CO2 and H2O. J Catal 2009;263:18995. doi:10.1016/j.jcat.2009.02.012.

[20] Tanaka H, Kuriyama M, Ishida Y, Ito S, Tomishige K, Kunimori K. Preferential CO oxidation in hydrogen-rich stream over Pt catalysts modified with alkali metals. Appl Catal A Gen 2008;343.

[21] Song C. Fuel processing for low-temperature and high-temperature fuel cells Challenges, and opportunities for sustainable development in the 21st century. Catal Today 2002;77:17-49.

[22] Lobera MP, Téllez C, Herguido J, Menéndez M. Catalytic purification of H2-rich streams by CO-PROX over Pt-Co-Ce/gamma-Al2O3 in fluidized bed reactors. Catal Today 2010;157:404-9. doi:10.1016/j.cattod.2010.01.051.

[23] Miyake T, Hamada M, Sasaki Y, Oguri M. Direct synthesis of phenol by hydroxylation of benzene with oxygen and hydrogen. Appl Catal A Gen 1995;131:33-42.

[24] Wcław a., Nowińska K, Schwieger W. Benzene to phenol oxidation over iron exchanged zeolite ZSM-5. Appl Catal A Gen 2004;270:151-6. doi:10.1016/j.apcata.2004.04.032.

[25] Yuranov I, Bulushev D a., Renken A, Kiwi-Minsker L. Benzene to phenol hydroxylation with N2O over Fe-Beta and Fe-ZSM-5: Comparison of activity per Fe-site. Appl Catal A Gen 2007;319:128-36. doi:10.1016/j.apcata.2006.11.023.

[26] Gimeno MP, Soler J, Herguido J, Menéndez M. Use of Fluidized Bed Reactors for Direct Gas Phase Oxidation of Benzene to Phenol. Ind Eng Chem Res 2010;49:6810-4. doi:10.1021/ie901706y.

[27] Spivey JJ, Hutchings G. Catalytic aromatization of methane. Chem Soc Rev 2014;43:792803. doi:10.1039/c3cs60259a.

[28] Wang L, Tao L, Xie M, Xu G, Huang J, Xu Y. Dehydrogenation and aromatization of methane under non-oxidizing conditions. Catal Letters 1993;21:35-41. doi:10.1007/BF00767368.

[29] Gimeno MP, Soler J, Herguido J, Menéndez M. Counteracting catalyst deactivation in methane aromatization with a two zone fluidized bed reactor. Ind Eng Chem Res 
2010;49:996-1000. doi:10.1021/ie900682y.

[30] Menéndez M, Herguido J, Téllez C, Soler J, Gimeno MP. United States Patent. US 8697962, 2014.

[31] García G, Campos E, Fonts I, Sánchez JL, Herguido J. Gas catalytic upgrading in a twozone fluidized bed reactor coupled to a cogasification plant. Energy and Fuels 2013;27:2835-45. doi:10.1021/ef400227z.

[32] Basile A. Handbook of membrane reactors. Volume 2, Reactor types and industrial applications. 2013.

[33] Stankiewicz A. Reactive separations for process intensification: an industrial perspective. Chem Eng Technol 2003;42:137-44.

[34] Collins JP, Schwartz RW, Hagen GP, Udovich CA. Catalytic Dehydrogenation of Propane in Hydrogen Permselective Membrane Reactors. Ind Eng Chem Res 1996;5885:4398405.

[35] Patil CS, van Sint Annaland M, Kuipers JAM. Fluidised bed membrane reactor for ultrapure hydrogen production via methane steam reforming: Experimental demonstration and model validation. Chem Eng Sci 2007;62:2989-3007. doi:10.1016/j.ces.2007.02.022.

[36] Gimeno MP, Wu ZT, Soler J, Herguido J, Li K, Menéndez M. Combination of a Two-Zone Fluidized Bed Reactor with a Pd hollow fibre membrane for catalytic alkane dehydrogenation. Chem Eng J 2009;155:298-303. doi:10.1016/j.cej.2009.06.037.

*Where the combination of a TZFBR with membranes was shown for the first time

[37] Medrano JA, Julián I, García-García FR, Li K, Herguido J, Menéndez M. Two-zone fluidized bed reactor (TZFBR) with palladium membrane for catalytic propane dehydrogenation: Experimental performance assessment. Ind Eng Chem Res 2013;52:3723-31. doi:10.1021/ie303185p.

[38] Medrano JA, Julián I, Herguido J, Menéndez M. Pd-Ag membrane coupled to a two-zone fluidized bed reactor (TZFBR) for propane dehydrogenation on a Pt-Sn/MgAl2O4 catalyst. Membranes (Basel) 2013;3:69-86. doi:10.3390/membranes3020069.

[39] Ugarte P, Durán P, Lasobras J, Soler J, Menéndez M, Herguido J. Dry reforming of biogas in fluidized bed: Process intensification. Int J Hydrogen Energy 2017:in press. doi:10.1016/j.ijhydene.2016.12.124.

[40] Gascón J, Téllez C, Herguido J, Jakobsen HA, Menéndez M. Modeling of fluidized bed reactors with two reaction zones. AIChE J 2006;52:3911-23. doi:10.1002/aic.11002.

[41] Julián I, Herguido J, Menéndez M. A non-parametric bubble size correlation for a TwoSection Two-Zone Fluidized Bed Reactor (TS-TZFBR). Powder Technol 2014;256:146-57. doi:10.1016/j.powtec.2014.02.004.

[42] Julián I, Herguido J, Menéndez M. Particle mixing in a two-section two-zone fluidized bed reactor. experimental technique and counter-current back-mixing model validation. Ind Eng Chem Res 2013;52:13587-96. doi:10.1021/ie401334x.

[43] Julián I, Gallucci F, van Sint Annaland M, Herguido J, Menéndez M. Coupled PIV/DIA for 
fluid dynamics studies on a Two-Section Two-Zone Fluidized Bed Reactor. Chem Eng J 2012;207-208:122-32. doi:10.1016/j.cej.2012.06.015.

[44] Julián I, Gallucci F, van Sint Annaland M, Herguido J, Menéndez M. Hydrodynamic study of a Two-Section Two-Zone Fluidized Bed Reactor with an immersed tube bank via PIV/DIA. Chem Eng Sci 2015;134:238-50. doi:10.1016/j.ces.2015.05.009.

[45] Knox W, Montgomery P, Moore R. Production of stilbene and styrene, 1976.

[46] Soler J, Lopez Nieto J, Herguido J, Menéndez M, Santamaría J. Oxidative Dehydrogenation of n-Butane in a Two-Zone Fluidized-Bed Reactor. Ind Eng Chem Res 1999;38:90-7.

[47] Rubio O, Herguido J, Menéndez M. Two-zone fluidized bed reactor for simultaneous reaction and catalyst reoxidation: Influence of reactor size. Appl Catal A Gen 2004;272:321-7. doi:10.1016/j.apcata.2004.06.004.

[48] Rubio O, Mallada R, Herguido J, Mene M. Experimental Study on the Oxidation of Butane to Maleic Anhydride in a Two-Zone Fluidized Bed Reactor. Ind Eng Chem Res 2002;41:5181-6.

[49] Gascón J, Téllez C, Herguido J, Menéndez M. A two-zone fluidized bed reactor for catalytic propane dehydrogenation. Chem Eng J 2005;106:91-6. doi:10.1016/j.cej.2004.11.005.

[50] Callejas C, Soler J, Herguido J, Menéndez M, Santamaría J. Catalytic dehydrogenation of $\mathrm{n}$-butane in a fluidized bed reactor with separate coking and regeneration zones. Stud Surf Sci Catal 2000;130:2717-22. doi:10.1016/S0167-2991(00)80881-2.

[51] Lobera MP, Téllez C, Herguido J, Menéndez M. Pt-Sn/MgAl ${ }_{2} \mathrm{O}_{4}$ as $n$-Butane Dehydrogenation Catalyst in a Two-Zone Fluidized-Bed Reactor. Ind Eng Chem Res 2009;48:6573-8. doi:10.1021/ie900381p.

[52] Duran P, Ugarte P, Soler J, Herguido J, Menendez M. Pure hydrogen production from biogas: intensified methane dry reforming in a two-zone fluidized bed reactor using permselective membranes. 10th World Congr. Chem. Eng., Barcelona: 2017. 
Table 1. First developments on fluidized bed catalytic reactors where reduction and oxidation zones are present simultaneously [1]

\begin{tabular}{|l|l|l|l|}
\hline Reaction & Catalyst & Main finding & Reference \\
\hline Oxidative coupling of methane & $\mathrm{MnP} / \mathrm{SiO}_{2}$ & $\begin{array}{l}\text { Separation of oxidation and } \\
\text { reaction zones }\end{array}$ & {$[6]$} \\
\hline $\begin{array}{l}\text { Oxidative dehydrogenation of } \\
\text { butane and propane }\end{array}$ & $\mathrm{V} / \mathrm{MgO}$ & Increased butadiene yield & {$[46]$} \\
\cline { 3 - 5 } & $\begin{array}{l}\text { Confirmation in larger } \\
\text { diameter reactor }\end{array}$ & {$[47]$} \\
\hline $\begin{array}{l}\text { Oxidation of butane to maleic } \\
\text { anhydride }\end{array}$ & $\mathrm{VPO}$ & $\begin{array}{l}\text { Feasibility of operation } \\
\text { with high butane content } \\
\text { in the feed }\end{array}$ & {$[48]$} \\
\cline { 1 - 3 } Dehydrogenation of propane & $\mathrm{Cr}_{2} \mathrm{O}_{3} / \mathrm{Al}_{2} \mathrm{O}_{3}$ & Stable operation & {$[49]$} \\
\cline { 1 - 3 } Dehydrogenation of butane & & {$[50]$} \\
\hline
\end{tabular}



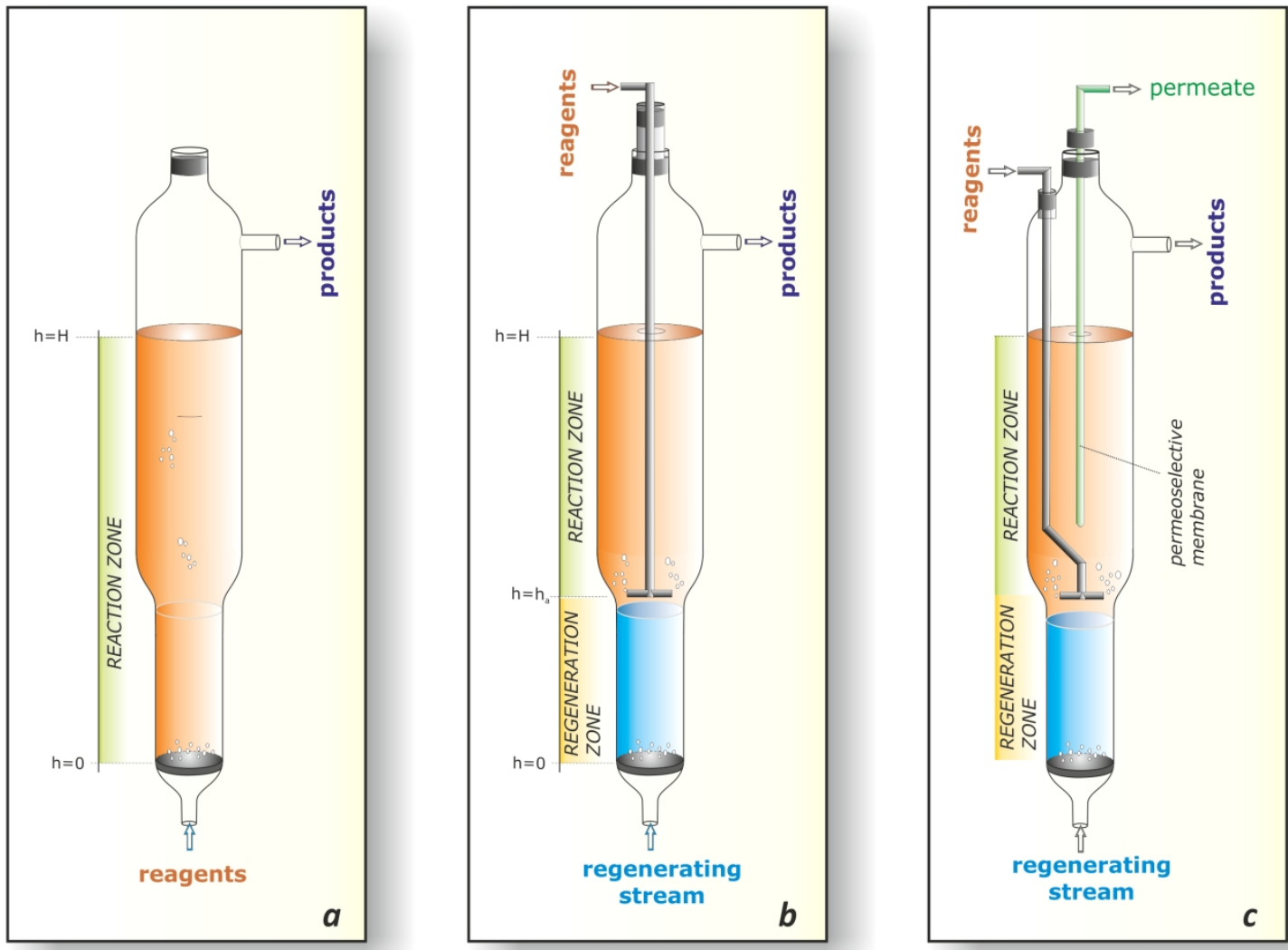

Figure 1.-

FBR (a), TZFBR (b) and TZFBR+MB (c) configurations 


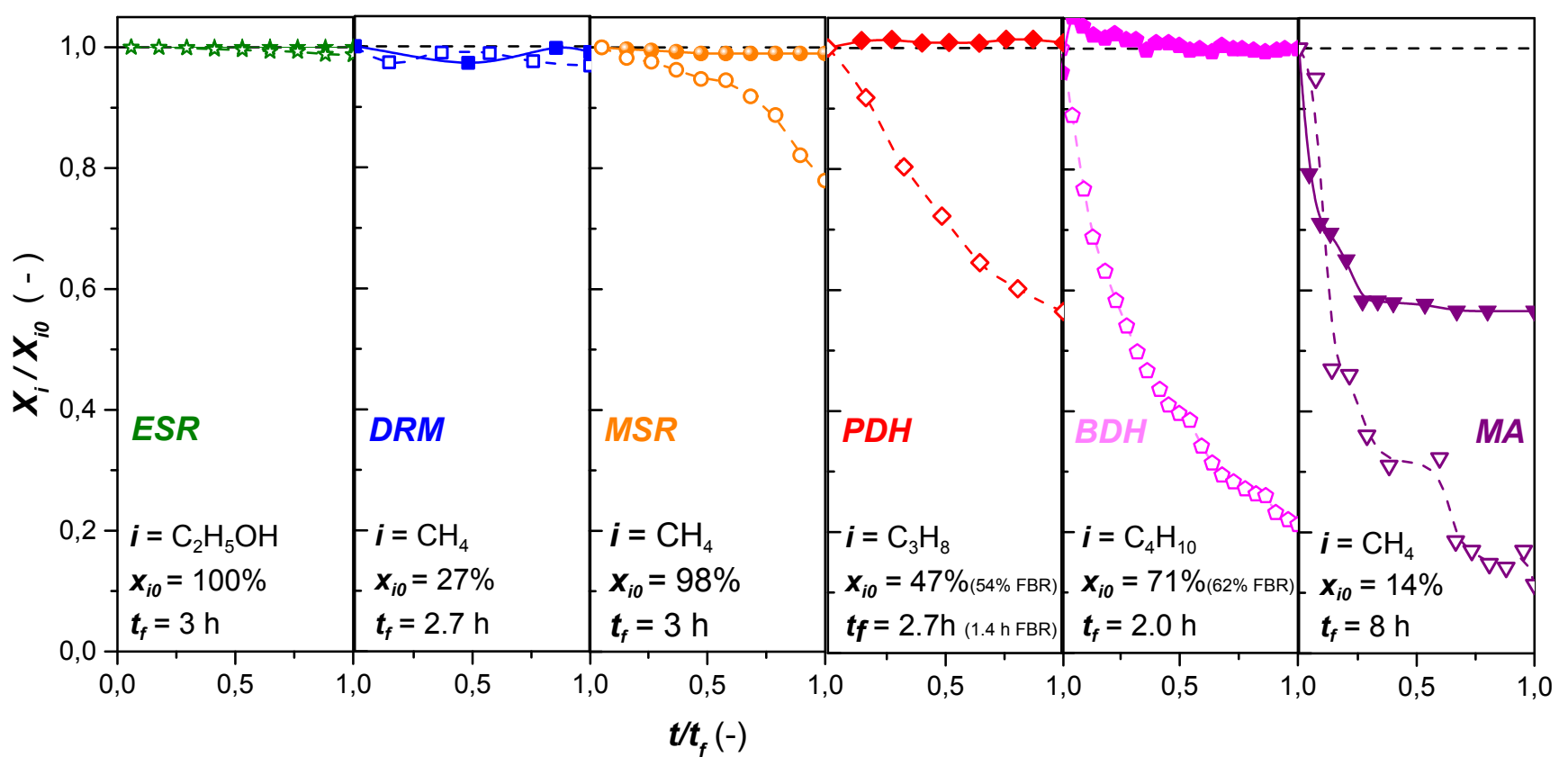

Figure 2.-

Stability plot.- Time evolution of $\boldsymbol{i}$ conversion for both, conventional FBR (empty symbols) and innovative TZFBR configurations (solid symbols), and different reaction processes. Conversions have been normalized dividing by the specific conversion at the beginning of the run $\left(\boldsymbol{x}_{i 0}\right)$. Likewise, time has been normalized with respect to the final time-on-stream of the experiments for each reaction process $\left(\boldsymbol{t}_{f}\right)$. ESR: Ethanol Steam Reforming [17] , DRM: Dry Reforming of Methane [38]; MSR: Methane Steam Reforming [11]; PDH: Propane Dehydrogenation [36]; BDH: Butane Dehydrogenation[51] ; MA: Methane Aromatization [28] 


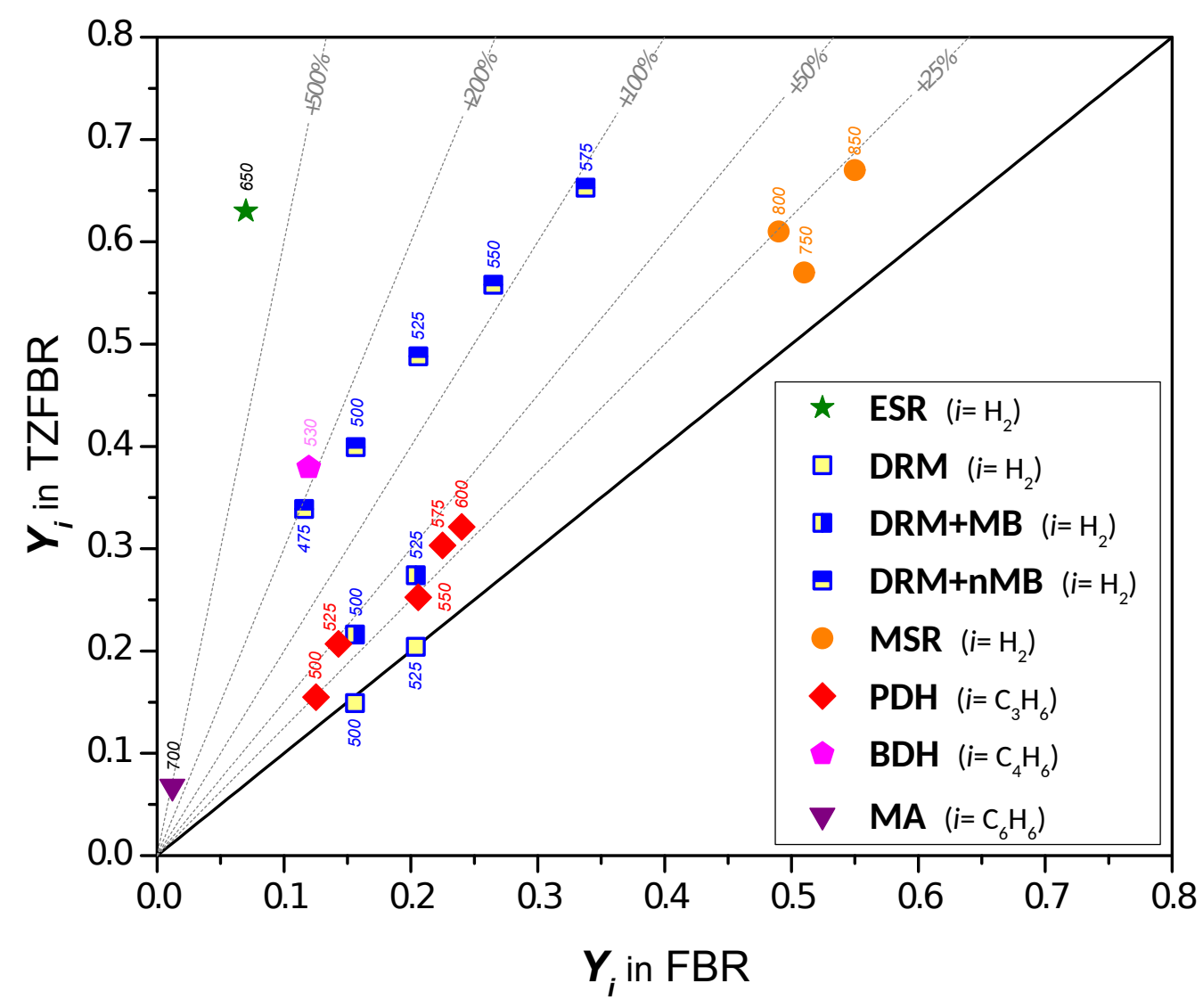

Figure 3.-

Parity plot for different processes comparing the yield (at time $t_{f}$ ) to the desired product (i) when using a TZFBR configuration vs. when a conventional FBR configuration was used. The symbols are the same as in Figure 2; in addition DRM+MB stands for Dry Reforming of Methane in TZFBR with membranes [38] and DRM+nMB is the same with twice the surface area of membranes inside the fluidized bed [52]. The data attached to the symbols represent the working temperature in ${ }^{\circ} \mathrm{C}$. 
- Review on advances in two-zone fluidized bed reactors

- New applications, including reforming of methane or ethanol

- New contributions to the design of the reactor

- Combination of TZFBR with membranes 